\title{
Editorial
}

Section D of the National Bureau of Standards Journal of Research has taken on a new form. Starting with this issue, the U.S. National Committee of URSI joins NBS in sponsoring the journal. Simultaneously, its title has been changed from "RADIO PROPAGATION" to "RADIO SCIENCE," to reflect the broadened scope of the journal sponsorship.

RADIO SCIENCE is expected to serve as the principal publication outlet of the scientific activities of the U.S. National Committee of URSI, and for the research programs of the NBS Central Radio Propagation Laboratory. RADIO SCIENCE will also carry selected papers from the NBS Radio Standards Laboratory and invited papers from recognized authorities in the field of radio science.

Because of the time taken to review and print the papers (approximately six months) it is expected that it will be several months before the broadened scope of the journal is fully realized.

With regard to the submission of manuscripts intended for publication in RADIO SCIENCE, it is requested that non-NBS authors send the original plus two copies to the URSI editor, Professor L. A. Manning. NBS authors should submit the original plus two copies to Dr. C. G. Little. All authors are specifically requested to follow the "Instructions to Authors" (see p. 137) in preparing their manuscripts. Strict attention to such details as format of references, number of copies to be submitted, etc., will significantly speed the review and publication process.

This first issue of RADIO SCIENCE is devoted to the Proceedings of the Symposium on the Ionospheric Propagation of Very Low Frequency Electromagnetic Waves, held at the Central Radio Propagation Laboratory, National Bureau of Standards, Boulder, Colorado, on 12, 13, and 14 August 1963. The papers are devoted to subjects of current importance in terrestrial VLF propagation with emphasis being placed on the effects of the ionosphere. Subjects covered include mode theory, theory of formation and physical characteristies of the lower ionosphere, and observations of VLF propagation under normal and disturbed conditions.

The Editors are greatly indebted to Mr. Douglass D. Crombie who acted as Guest Editor of this special issue as well as Chairman of the Technical Program Committee.

\section{G. Litthe}

Central Radio Propagation Laboratory

Boulder Laboratories

National Bureau of Standards

Boulder, Colorado
L. A. Manning

Radioscience Laboratory

Stanford University

Stanford, California 